\title{
An improved dinitrosalicylic acid method for determining blood and cerebrospinal fluid sugar levels
}

\author{
A. F. MOHUN AND I. J. Y. COOK \\ From the Archway Group Laboratory and New End Laboratory \\ (Archway Group), London
}

SYNOPSIS A development of a technique for estimating sugar in blood, cerebrospinal fluid, etc., is described, using 3:5-dinitrosalicylic acid (D.N.S.A.) originally introduced by Sumner (1921).

Results can be obtained in less than 10 minutes if required. The method is well suited to the estimation of random blood sugars and the handling of diabetic clinic requirements in hospital laboratories. The reagents are cheap, stable, and easily prepared. The results are very close to true glucose values in blood and cerebrospinal fluid. The technique has justified its existence in a busy clinical laboratory on the grounds of simplicity and rapidity, and is sufficiently precise for all ordinary work.

Forty years ago Sumner described the use of 3:5-dinitrosalicylic acid (D.N.S.A.) for the measurement of glucose in the urine of diabetics (Sumner, 1921). The technique depends upon the development of a red colour in solutions containing D.N.S.A. and glucose (or other reducing sugar) when heated in a boiling water-bath together with reducing agents and alkali and phenol. In subsequent papers (Sumner, 1924, 1925) the reagents were refined and improved.

Leech and Woodford (1948) adapted the method to the bedside estimation of blood sugar in the range from $75 \mathrm{mg}$. per $100 \mathrm{ml}$. upward. These authors combined the D.N.S.A. and the other reagents in one mixture: the stability of this mixture was called in question by Hall (1950).

Sumner and Sisler (1944) adapted the D.N.S.A. method to the estimation of glucose in blood as a full-scale laboratory procedure, and reported evidence that the failure of the method hitherto when used with test fluids containing less than some $70 \mathrm{mg}$. glucose per $100 \mathrm{ml}$. was due to loss of glucose (by oxidation and by caramelization) before colour could develop. To avoid these losses, the authors evaporated protein-free filtrates to dryness and then took up the residues in a composite colour reagent containing D.N.S.A., alkali, phenol, and sulphite. This procedure gave a linear response when glucose concentrations were plotted against colour developed Received for publication 30 March 1961. but the method is too laborious for routine work with large numbers of specimens.

Lee (1954) made a significant advance. He used the D.N.S.A. as both protein precipitant and colour reagent, and described a method for use by general practitioners for distinguishing between hypo- and hyper-glycaemia, and for measuring blood sugar in the range from about $70 \mathrm{mg}$. per $100 \mathrm{ml}$. up to several hundred $\mathrm{mg}$. per $100 \mathrm{ml}$. with reasonable accuracy. Further, his method can give a result in as little as six minutes from the time of taking the blood from the patient. The original limitation remained, however: when the test fluid contained less than some $70 \mathrm{mg}$. per $100 \mathrm{ml}$., the colour developed was faint and irregular in amount. This was of no great importance in relation to the purpose for which Lee proposed the method but it invalidated the method for routine laboratory use.

The 'dose-response' curve produced when glucose solutions are caused to react with Lee's reagents (reagent A being a solution of D.N.S.A., reagent B a phenol-alkali-sulphite mixture) is shown in Fig. 1 (line a). This curve shows that if the concentration of glucose in the final reaction mixture is kept above some $3 \mathrm{mg}$. per $100 \mathrm{ml}$. the relation between colour produced and glucose concentration is linear over a wide range. The problem then was to achieve these conditions without introducing the large errors usually associated with high blank values. We therefore tried the effect of adding the glucose, in the 


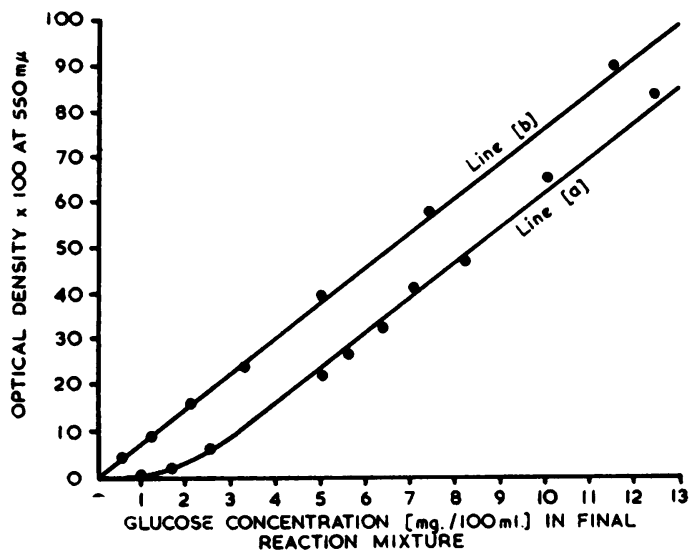

FIG. 1. Relation between optical density of reaction mixture at $550 \mathrm{~m}_{\mu}$ and glucose content.

form of a relatively large volume of accurately measured dilute solution, in precisely similar manner to each of three tubes containing aliquots of (respectively) the specimen to be tested, a standard glucose solution, and a water blank. This is achieved in the manner described below by the addition of glucose to the D.N.S.A. solution (Lee's reagent A) to give a reagent which we refer to as 'glucoseD.N.S.A.' When this reagent (containing approximately $10 \mathrm{mg}$. glucose per $100 \mathrm{ml}^{1}$ ) is used to measure the glucose content of graded solutions, a straight-line relationship is observed between colour developed and glucose content, as shown in line b in Fig. 1. This modification renders the method suitable for use in routine work. Having established this, we have investigated the accuracy and the reproducibility of the method; the stability of the reagents; the effects of delays and interruptions during the procedure; the optimal proportions of test fluid volume to reagent volume; and the effect of using D.N.S.A. in the precipitation of protein in the test fluid. We have also compared the results by the technique finally adopted with those obtained by the Hagedorn and Jensen technique performed by an experienced technologist and by the glucoseoxidase technique of Marks (1959). The results have been satisfactory because this technique is the simplest known to us, is capable of giving a result in less than 10 minutes if required, and lends itself to the estimation of specimens arriving at irregular intervals as well as to the handling of large batches.

\section{METHOD}

Blood or other fluid to be tested is mixed with glucoseD.N.S.A. (usually in the proportion $1: 20$ ) and centri-

'It yields some $5 \mathrm{mg}$. glucose per $100 \mathrm{ml}$. after addition of reagent B. fuged. A portion of the clear supernatant is added to a equal volume of Lee's reagent $B$ and heated in a boiling. water-bath for not less than three minutes. The red. colour developed is compared with that produced by standard glucose solution and a water blank, both prog cessed 'as blood'.

REAGENTS The following were made up:-

Stock 3:5-dinitrosalicylic acid solution (Lee's reagen $A)^{2}$ 3:5-dinitrosalicylic acid (D.N.S.A.), $17 \cdot 5 \mathrm{~g}$., is placed in $1,000 \mathrm{ml}$. of hot distilled water (at about $60^{\circ} \mathrm{C}$.) anक stirred to dissolve.

The solution is filtered through a rapid paper to clarify Crystallization occurs on prolonged standing below? about $15^{\circ} \mathrm{C}$., so the solution is stored in an incubator as $25^{\circ} \mathrm{C}$. or $37^{\circ} \mathrm{C}$. It is stable for many weeks (possibly indefinitely) at either of these temperatures.

Glucose-D.N.S.A. One volume of $1 \%(\mathrm{w} / \mathrm{v})$ glucos in saturated benzoic acid solution is added to $100 \mathrm{vol}$. of stock $1.75 \%(w / v)$ D.N.S.A. prepared as above, and mixed thoroughly by repeated inversion of the stoppere $\bar{P}$ container. This reagent is kept in a distinctive container marked to avoid confusion with the stock D.N.S.A. solution and is stored at $25^{\circ} \mathrm{C}$. or $37^{\circ} \mathrm{C}$. Glucose in this environment appears to be as stable as in the con? ventional saturated benzoic acid solution: the glucoses D.N.S.A. can certainly be used for many weeks.

LEE'S REAGENT B Phenol, $13.8 \mathrm{~g}$., and $13.8 \mathrm{~g}$. sodiun bisulphite $\left(\mathrm{NaHSO}_{3}\right)$ are dissolved in $350 \mathrm{ml}$. of $10 \%$ $\mathrm{NaOH}$ and added to a solution of $510 \mathrm{~g}$. potassium sodium-tartrate (analytical grade) in $880 \mathrm{ml}$. of wate? The sodium bisulphite can be added as $27 \mathrm{ml}$. of @ solution containing $38 \%$ weight for weight $(51 \cdot 1 \mathrm{~g}$. pe $\overrightarrow{5}$ $100 \mathrm{ml}$.) $\mathrm{NaHSO}_{3}$. Solution of the potassium-sodiumb tartrate is hastened by gentle warmth (not above $45^{\circ} \mathrm{C}$.) $\mathrm{P}$

The final solution should be filtered through a rapiक paper to clarify. Stored at room temperature in a tem perate climate the reagent is stable for at least ning months.

STOCK SOLUTIONS OF GLUCOSE Standard solutions corf taining $100 \mathrm{mg}$. per $100 \mathrm{ml}$. and $300 \mathrm{mg}$. per $100 \mathrm{ml}$. are prepared in saturated benzoic acid solution and are processed as blood in the routine technique.

SPECIMENS OF BLOOD The conventional method of coF lecting specimens in fluoride or fluoride-oxalate mixturf is satisfactory. Sequestrene, in the concentrations used for haematological specimens, does not interfere.

Ordinary $0.1 \mathrm{ml}$. and $0.2 \mathrm{ml}$. straight pipettes, calibrated to contain, can be used if it is necessary to take blood from a capillary puncture. In this case, the contents

2 D.N.S.A. from Messrs. Hopkin and Williams Ltd., marketed 'general purpose reagent', has given consistently satisfactory results, as also has that supplied by Messrs. Kodak Ltd. From another manufacturer certain batches have proved unsatisfactory in that the gave only some $75 \%$ of the expected intensity of colour; the firm concerned reported that this was due to critical concentrations of iron and sulphate, and they described tests for these. However, the simplest test of any batch is to use it and to observe that the optica density given by the $100 \mathrm{mg}$. per $100 \mathrm{ml}$. standard glucose solution io the routine test procedure lies close to $0 \cdot 17$. 
the pipette are delivered into the glucose-D.N.S.A., which is drawn up and down until the mixture is evenly distributed between the test-tube and the lumen of the pipette. The precipitated protein is subsequently removed from the pipette by drawing an alkaline cleaning solution up and down its lumen, and then leaving the pipette in the solution for an hour or two.

\section{ROUTINE BLOOD SUGAR ESTIMATIONS IN BATCHES}

The first three of a row of 3 in. $\times \frac{1}{2}$ in. $(75 \times 12.5 \mathrm{~mm}$. $)$ tubes are labelled $B, 100$, and 300 respectively; the remainder are labelled to correspond with the specimens of blood to be tested.

The first three tubes receive respectively $0.20 \mathrm{ml}$. of distilled water, $0.20 \mathrm{ml}$. of $100 \mathrm{mg} . / 100 \mathrm{ml}$. glucose solution, and $0.20 \mathrm{ml}$. of $300 \mathrm{mg} . / 100 \mathrm{ml}$. glucose solution delivered with the same type of pipette as that used to place $0.20 \mathrm{ml}$. of blood in each of the remaining tubes.

Glucose-D.N.S.A., $4.0 \mathrm{ml}$., is added to each tube, the first $3 \mathrm{ml}$. being blown in to break up the blood, and the remaining $1 \mathrm{ml}$. being allowed to drain in a standard fashion so that each tube receives as nearly as possible the same volume of dinitrosalicylic acid. It is not important that this volume be precisely $4.0 \mathrm{ml}$., but it is important that exactly the same volume be delivered into each tube. (The effect of large alteration in the volume of D.N.S.A. used throughout is described below.)

The contents of each tube are mixed thoroughly for about 10 seconds by repeated inversion, those of blank and standards just as thoroughly as the rest; soft plastic stoppers $^{1}$ are useful because they are light enough to allow of centrifugation without being driven into the tubes. The tubes containing blood show the brown colour of acid haematin and the opacity of precipitated protein. All tubes are spun at about 3,000 r.p.m. for two or three minutes; at lower speeds such as 2,000 r.p.m. in the ordinary small centrifuge some $1 \%$ of specimens will show that the supernatant does not clear completely. Such incomplete clearing is due to the chance operation of unknown factors, for it is not reproducible at will using the same specimen; it is not due to allowance of insufficient time; it is entirely avoided by spinning at 3,000 r.p.m. (or by filtration through a fine paper such as Whatman No. 42). The precipitate formed by D.N.S.A. and blood comes down compactly, and the clear yellow supernatant is sampled without disturbing the deposit.

A bulb pipette is used to transfer $2 \mathrm{ml}$. volumes from each tube to suitably labelled 6 in. $\times \frac{5}{8}$ in. $(150 \times 15 \mathrm{~mm}$.) test tubes. The clarity of the contents of each tube is confirmed at a glance, and then $2 \mathrm{ml}$. volumes of Lee's reagent $B$ are added to each tube and mixed. Quite vigorous shaking is without effect on the yield of glucose. (The specific gravity of reagent B is high, and therefore mixing is not automatic.)

The tubes are placed in a boiling water-bath. The safe minimum period for full colour development is three minutes at $100^{\circ} \mathrm{C}$, , but many water-baths are so constructed that the entry of a full load of cold tubes causes

'Supplied by Arnold R. Horwell, 18, Christchurch Avenue, London, N.W.6, England. the water to cease boiling for a minute or more, the temperature dropping temporarily to about $96^{\circ} \mathrm{C}$. For this reason we have adopted a six-minute period as the routine procedure with large batches. This period does not need to be accurately measured; the effect of varying the time of heating between three and 30 minutes is shown in Table I.

The tubes are then cooled in water at room temperature for a few minutes. The colorimeter is set at zero with the contents of the blank tube in a $5 \mathrm{~mm}$. cuvette, using a yellow-green filter (e.g., Ilford 605, with maximum absorption at $550 \mathrm{~m} \mu$ ). In these conditions, the $100 \mathrm{mg} . / 100 \mathrm{ml}$. glucose standard gives an optical density of around $0 \cdot 17$, and the $300 \mathrm{mg} . / 100 \mathrm{ml}$. standard reads at about 0.51 . The relation between optical density and reducing sugar content of the solutions obeys Beer's law very closely in these conditions (Fig. 1).

\section{SINGLE ESTIMATIONS AT FREQUENT INTERVALS}

There arise situations in clinical laboratories which demand that individual patients attending clinics should have blood sugar estimations made in the minimum time after their arrival. In such cases it is convenient to put through duplicate blanks, and two standards each in duplicate, with the first specimen to be estimated, and to use these for calculating the results of subsequent isolated estimations. This procedure allows a diabetic clinic to proceed as fast as the clinician desires, once the first patient has been 10 minutes in the hospital.

Two points arise for consideration: first, it is necessary to guard against the possibility that the optical density of the blanks and standards may occasionally depart from the normal by an excessive amount, leading to an unduly large constant error in the calculation of all the tests based thereon. The use of duplicates for blank and standards is sufficient safeguard in this respect, provided that in the rare case when the duplicates are not in reasonable agreement with each other (within $8 \%$ ) further replicates are put through to identify the atypical reading.

Secondly, it is necessary to be assured that the absence of individual blanks and standards does not lead to an unduly large range of variation in the tests. This point was investigated by taking routine specimens of blood, adding $1.0 \mathrm{ml}$. volumes to $20 \mathrm{ml}$. volumes of glucose-D.N.S.A., spinning, adding accurate $2.0 \mathrm{ml}$. volumes of the supernatant to similar volumes of reagent $B$, and heating in the routine manner; blanks and standards were put through with each single $2.0 \mathrm{ml}$. aliquot, and the results in each batch were calculated in two ways: each aliquot's reading was made with reference to (1) its own blank and standards, and (2) blank and standards put through with the first aliquot of each batch, simulating the procedure at a diabetic clinic.

Table II shows that the diabetic clinic procedure yields a slightly increased coefficient of variation between runs, but the figure of $3.4 \%$ quoted in Table II was obtained with only single estimations of blank and standards: the use of duplicate blanks and standards would reduce this to a point between $3.4 \%$ and $2.4 \%(1 / \sqrt{ } 2 \times 3.4 \%)$. 
TABLE I

EFFECT OF VARYING PERIOD OF HEATING

\begin{tabular}{|c|c|c|c|c|}
\hline $\begin{array}{l}\text { Time of Heating } \\
\text { (min.) }\end{array}$ & $\begin{array}{l}\mathrm{l} \text { Reagent Blanks Against } \\
\mathrm{H}_{2} \mathrm{O}\end{array}$ & $\begin{array}{l}2105 \mathrm{mg} . / 100 \mathrm{ml} . \\
\text { Glucose Against Reagent } \\
\text { Blank }\end{array}$ & $\begin{array}{l}3315 \mathrm{mg} . / 100 \mathrm{ml} . \\
\text { Glucose Against Reagent } \\
\text { Blank }\end{array}$ & $\begin{array}{l}\text { Ratio between } \\
3 \text { and } 2\end{array}$ \\
\hline 3 & $\begin{array}{c}325-365^{1} \\
355^{2}\end{array} \quad(99 \%)^{3}$ & $\begin{array}{c}180-195 \\
185\end{array}(97 \%)$ & $\begin{array}{l}555-580 \\
565\end{array}$ & $3.06(100 \%)^{4}$ \\
\hline 6 & $\begin{array}{c}340-370 \\
360\end{array}(100 \%)$ & $\begin{array}{c}170-205 \\
190\end{array}(100 \%)$ & $\begin{array}{c}560-590 \\
580\end{array}(100 \%)$ & $3.05(100 \%)$ \\
\hline 10 & $\begin{array}{l}350-380 \\
370\end{array}(103 \%)$ & $\begin{array}{l}175-205 \\
195\end{array}(103 \%)$ & $\stackrel{565-600}{585}(101 \%)$ & $3.00(98 \%)$ \\
\hline 15 & $\begin{array}{c}360-395 \\
380\end{array}(106 \%)$ & $\begin{array}{l}180-210 \\
195\end{array}(103 \%)$ & $\begin{array}{l}570-605 \\
585\end{array}(101 \%)$ & $3.00(98 \%)$ \\
\hline 20 & $\begin{array}{l}365-405 \\
390\end{array}(108 \%)$ & $\begin{array}{c}180-215 \\
195\end{array}(103 \%)$ & $\begin{array}{c}580-620 \\
600\end{array}(103 \%)$ & $3.08(101 \%)$ \\
\hline 30 & $\begin{array}{l}380-420 \\
400\end{array}(111 \%)$ & $\begin{array}{l}185-220 \\
205\end{array}(108 \%)$ & $\begin{array}{l}585-640 \\
620(107 \%)\end{array}$ & $3.02(99 \%)$ \\
\hline
\end{tabular}

The figures in the body of this table are optical densities expressed to the nearest 0.005 and multiplied by 1,$000 ; 0.20$ ml. volumes of water, $\overrightarrow{0}$ $105 \mathrm{mg} . / 100 \mathrm{ml}$., and $315 \mathrm{mg} . / 100 \mathrm{ml}$. glucose solutions were processed by the routine technique, the time of heating being varied between three $\sigma$ and 30 minutes. Column 1 shows the optical density of the reagent blanks against $\mathrm{H}_{2} \mathrm{O}$ as an index of absolute chromogenicity, and columns 2 and 3 the optical densities to be expected in routine work when zero setting is made with the reagent blank, containing glucose-D.N.S.A., using a $5 \mathrm{~mm}$. light path and Ilford 605 filter. It will be seen that the linearity of the dose-response is not disturbed by prolonged heating (beyond $\rightarrow$ 10 minutes), although the amount of colour developed is increased in all tubes.

${ }^{1}$ Range in six separate experiments.

${ }^{2}$ Mean of six separate experiments.

${ }^{3}$ Means expressed as a percentage of the six-minute mean.

${ }^{4}$ Ratios expressed as percentage of six-minute ratio.

TABLE II

EFFECT OF ADOPTING DIABETIC CLINIC PROCEDURE COMPARED WITH ROUTINE TECHNIQUE

Batch Made from

Blood Specimen

No. of Replicates

Results ( $\mathrm{mg} . / 100 \mathrm{ml}$.)

\begin{tabular}{|c|c|c|c|c|c|}
\hline & & \multicolumn{2}{|c|}{ Diabetic Clinic Procedure } & \multicolumn{2}{|c|}{ Routine Procedure } \\
\hline & & Range & Mean & Range & Mean \\
\hline $\mathbf{A}$ & 7 & $149-156$ & 152 & $149-160$ & 154 \\
\hline B & 9 & $75-86$ & 80 & $78-88$ & 83 \\
\hline $\mathrm{C}$ & 9 & $339-344$ & 342 & $326-370$ & 344 \\
\hline D & 9 & $126-134$ & 132 & $134-139$ & 137 \\
\hline $\mathbf{E}$ & 9 & $78-94$ & 83 & $77-87$ & 83 \\
\hline
\end{tabular}

Coefficient of variation between runs (routine procedure) $=3 \cdot 1 \%$

Coefficient of variation between runs (diabetic clinic procedure) $=3 \cdot 4 \%$.

Coefficient of variation between procedures (based on 43 paired comparisons) $=2.7 \%$.

When comparing these figures with the overall coefficient of variation between replicates by the routine technique (see Table XI) it should be remembered that errors arising from pipetting $0.2 \mathrm{ml}$. amounts of test fluid and adding $4.0 \mathrm{ml}$. amounts of glucose-D.N.S.A. are not present in the figures of Table II, because the mixing of blood and glucose-D.N.S.A. was performed in bulk in these batches as described above.

\section{TECHNIQUE FOR USE WITH THE EEL PORTABLE TYPE COLORIMETER (LOW-POWER LAMP)}

This instrument can be operated with round tubes of $7 \mathrm{~mm}$. diameter requiring only $2 \mathrm{ml}$. of solution to obtain a reading. Half-volumes are used throughout, and the blank is set at about 0.30 , this figure being then subtracted from the readings of standards and tests. Filter 625 is preferable to filter OGR1 (Table III). The use of
3 in. $\times \frac{3}{8}$ in. $(75 \times 10 \mathrm{~mm}$.) tubes at the first stage 을 facilitates removal of $1.0 \mathrm{ml}$. volumes of supernatant.

When estimating samples containing more than $300 \mathrm{mg}$. $/ 100 \mathrm{ml}$. glucose, the final solutions of blank, $N$ standards, and test should be diluted with water to bring $\mathrm{N}$ their optical densities down to measurable dimensions. O This procedure is legitimate with samples containing up to at least $2,000 \mathrm{mg}$. $/ 100 \mathrm{ml}$. (Table IV). The use of the glucose-D.N.S.A. reagent precludes any other type of dilution procedure. This fact should be made clear to all concerned with the routine use of the method.

\section{SPECIMENS OF CEREBROSPINAL FLUID}

When testing cerebrospinal fluid, the volume of glucoseD.N.S.A. can be reduced to $3.0 \mathrm{ml}$, , so that the $100 \mathrm{mg}$. $100 \mathrm{ml}$. glucose standard gives an optical density of 
TABLE III

OPTICAL DENSITIES OF GLUCOSE ${ }^{1}$ STANDARDS AGAINST BLANKS

\begin{tabular}{llc} 
& Filter 625 & Filter OGRI \\
\hline $100 \mathrm{mg} / 100 \mathrm{ml}$. glucose & $0.21^{2}(0.51$ minus 0.30$)$ & 0.17 \\
$200 \mathrm{mg} / 100 \mathrm{ml}$. glucose & $0.41(0.71$ minus 0.30$)$ & 0.33 \\
$300 \mathrm{mg} . / 100 \mathrm{ml}$. glucose & $0.59(0.89$ minus 0.30$)$ & 0.47
\end{tabular}

${ }^{1}$ Using half-volumes in an EEL portable type colorimeter.

${ }^{2}$ Each figure is the mean of triplicate determinations. When using filter 625 the reagent blank is set at 0.30 and this figure is deducted from test readings.

around $\mathbf{0} \cdot 22$. (The consumption of D.N.S.A. by protein precipitation is negligible in the case of cerebrospinal fluid.)

\section{RESULTS}

RATIO OF VOLUMES OF BLOOD AND D.N.S.A. REAGENT The use of glucose-D.N.S.A. as both proteinprecipitant and colour reagent involves an examination of the extent to which the consumption of D.N.S.A. by protein-precipitation affects the comiparison between the supernatants of the tests, blanks, and standards; there is no loss of D.N.S.A. in the blanks and standards, and therefore the optical density of the test supernatant may be understated to some extent, depending upon the fact that the blank may contain a significant excess of D.N.S.A. vis-à-vis the test. This point has been investigated.

In this connexion, we refer to the normal glucoseD.N.S.A. reagent as ' $100 \%$ D.N.S.A.', meaning that the D.N.S.A. content has not been reduced. The extent to which the D.N.S.A. concentration is reduced by protein-precipitation in the routine procedure was determined by titration of total acidity against $\mathrm{NaOH}$. This is not a specific titration of D.N.S.A., but the latter is such a strong acid that it seems reasonable to take total acidity as a measure of D.N.S.A. content in this situation.
Method Blood, $0.2 \mathrm{ml}$., was mixed with $4.0 \mathrm{ml}$. of D.N.S.A. solution $(1.75 \mathrm{~g} . / 100 \mathrm{ml}$.) and spun. Two $\mathrm{ml}$. of the supernatant was titrated against $\mathrm{N} / 10 \mathrm{NaOH}$, using B.D.H. universal indicator, to a greenish-yellow endpoint which was checked by $p \mathrm{H}$ meter to lie close to $p \mathrm{H}$ 7.0. A similar titration was performed substituting water for blood. The ratio between these two titrations gave a measure of the proportion by which the D.N.S.A. was reduced in concentration owing to combination with the precipitated protein.

In order to see how much variation there might be between individual specimens of blood in routine work, we examined 115 routine specimens in this way. The results are shown in Table V. These figures indicate that some $75 \%$ of the D.N.S.A. (in the $4 \mathrm{ml}$. of reagent) remains in solution after the precipitation

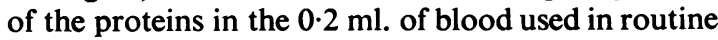
work. Experiments were therefore devised to determine the effect of using various concentrations of dinitrosalicylic acid. In these experiments we use the following terminology:- $B / 100, B / 75, B / 70$ denote blanks using $100 \%, 75 \%$, and $70 \%$ D.N.S.A. respectively, $100 \%$ D.N.S.A. being the 1.75 g./100 $\mathrm{ml}$. solution routinely used; $100 / 100,100 / 75$, and $100 / 70$ denote the $100 \mathrm{mg} . / 100 \mathrm{ml}$. glucose standard using $100 \%, 75 \%$, and $70 \%$ D.N.S.A. respectively; in general the first figure represents the glucose content of the fluid tested, and the second figure the strength of D.N.S.A. used.

As we were attempting to measure small changes in optical density we approached the problem in two ways: first we processed water blanks and standard glucose solutions exactly as blood in the routine technique, but using various strengths of dinitrosalicylic acid. This procedure required that the amount of glucose added to the D.N.S.A. be very accurately measured so that it should not itself cause variations in the final optical densities obtained when different strengths of D.N.S.A. were compared.

TABLE IV

LINEARITY OF DOSE-RESPONSE IN REGION OF HIGH BLOOD SUGAR LEVELS

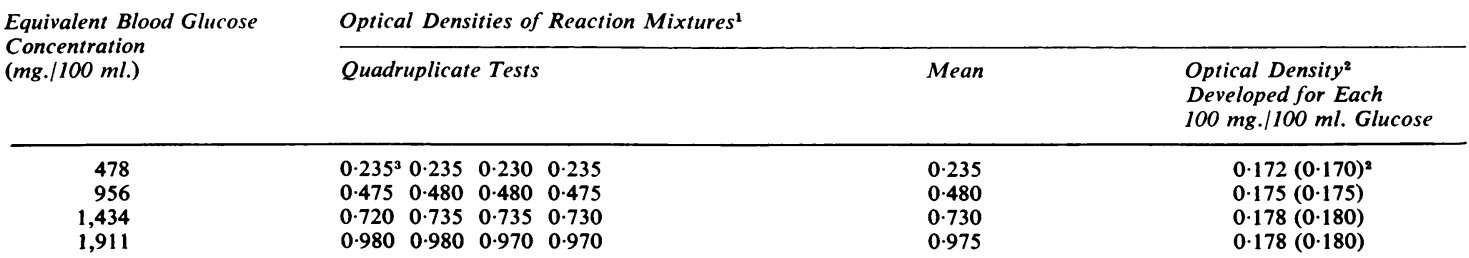

Solutions of glucose in D.N.S.A. were prepared, simulating the glucose content of the supernatant in the routine technique when samples of blood containing from $478 \mathrm{mg} . / 100 \mathrm{ml}$. to $1,911 \mathrm{mg} . / 100 \mathrm{ml}$. are estimated.

${ }^{1}$ The blank, standards, and tests were diluted with water, 10 vol. of water being added to 4 vol. reaction mixture.

${ }^{2}$ Readings made to the nearest 0.005 and calculated $O$.D. figures rounded-off to nearest 0.005 .

${ }^{3}$ Calculated for the undiluted reaction mixture by multiplying the observed $O$.D. of the diluted solution by $14 / 4$, and dividing by the glucose content of the test solution. 
TABLE V

RATIO OF VOLUMES OF BLOOD AND D.N.S.A. REAGENT

No. of Specimens Showing Each Percentage of Residual D.N.S.A. $(100 \%=1 \cdot 75 \mathrm{~g} .1100 \mathrm{ml}$.

$\begin{array}{lc}70 \% & \text { none } \\ 71 \% & 2 \\ 72 \% & 4 \\ 73 \% & 24 \\ 74 \% & 22 \\ 75 \% & 27 \\ 76 \% & 16 \\ 77 \% & 14 \\ 78 \% & 2 \\ 79 \% & 3 \\ 80 \% & 1 \\ 81 \% & \text { none } \\ \text { Total } & 115\end{array}$

${ }^{1}$ The scatter of the percentages approximates closely to a normal distribution, as would be expected of figures related directly to plasma protein concentrations.

Table VI summarizes the results of this first series of experiments. In interpreting these figures one must tear in mind that each is subject to some variation (estimated to be about 0.005 ) due to purely instrumental factors. In the range $70 \%$ to $80 \%$ D.N.S.A., the understatement of results in routine tests due to the use of $100 \%$ D.N.S.A. in the blanks ranges from 0.02 to 0.01 ; it seems reasonable to take the mean of these, i.e., 0.015 , as a representative estimate of this understatement. As the $100 \mathrm{mg}$./ $100 \mathrm{ml}$. glucose standard gives an optical density of close to 0.17 in the conditions of the routine tests, this understatement of 0.015 represents a deficiency of $(0.015 / 0.170 \times 100) \mathrm{mg} . / 100 \mathrm{ml} .=9 \mathrm{mg} . / 100 \mathrm{ml}$. in the results of routine tests. As in fact the results of routine tests are very close to 'true glucose' values, it follows that there must be compensating factors at work, non-glucose reducing substances in blood balancing against the above understatement.

Further examination of the figures in Table VI suggests the possibility that in the region of $300 \mathrm{mg}$./ $100 \mathrm{ml}$. there may be a small additional understatement of the results due to possible diminished chromogenicity of solutions containing less than $100 \%$ dinitrosalicylic acid. To investigate this point, and to eliminate some of the variability inherent $i \stackrel{\overrightarrow{8}}{\overrightarrow{8}}$ the procedure adopted in the first series of experiments, we carried out a second series of experiment in which graded series of glucose solutions in various concentrations of D.N.S.A. were prepared; the volumes chosen were suitably large and permitte the use of accurately calibrated pipettes and flask $\bar{S}$ The actual concentrations of the glucose solutions were chosen to correspond with those obtaining in routine tests; in the event it proved convenient t $\vec{\Phi}$ make solutions corresponding to $105 \%$ of those actually used in routine tests, this difference being of no significance in this context.

As in the first series, we repeated the $100 \%$ D.N.S.A. series with each lower concentration of D.N.S.A., so that differences in chromogenicity of individual batches were allowed for. The results ar shown in Tables VII and VIIA. These figures support the conclusion suggested by the first series, namely. that falling concentrations of D.N.S.A. do tend te give slightly lowered readings in the range of high glucose concentrations in routine tests but the effecf is of small consequence in the range $70 \%$ to $80 \%$ D.N.S.A.; it is only when the D.N.S.A. concentra tion has fallen to some $60 \%$ of the normal that the reduced chromogenicity shows itself, and then onlo in the range of high blood sugars $(300 \mathrm{mg} . / 100 \mathrm{me}$ upward).

We conclude, then, that in the routine metho described there is a constant understatement of some $9 \mathrm{mg} . / 100 \mathrm{ml}$. when blood is the test flui $\overrightarrow{\text { क्F }}$ this being counterbalanced in practice by the effect of non-glucose reducing substances so that the final figures are very close to true glucose values: and, further, the reduction in D.N.S.A. concentra tion met with in routine work (due to consumption in the precipitating of protein) is of no significance. except possibly in the case of very high blood sugais values, which may be slightly understated on this account.

Finally, it seemed of interest to show the effect of reducing the volume of D.N.S.A. solution used routine work from the $4 \mathrm{ml}$. used in the technique we describe to $3 \mathrm{ml}$. and $2.5 \mathrm{ml}$. Such changes increase the depth of colour developed by a giveng

TABLE VI

EFFECT OF CONSUMPTION OF D.N.S.A. BY PRECIPITATION OF PROTEIN IN FIRST SERIES OF EXPERIMENTS

$70 \%$ D.N.S.A. Against $100 \%$ D.N.S.A.

\begin{tabular}{ll}
\hline Optical & Density \\
\hline B/100 v. B/70 & 0.02 \\
$100 / 100$ v. B/100 & 0.17 \\
$100 / 70$ v. B/100 & 0.15 \\
$300 / 100$ v. B $/ 100$ & 0.53 \\
$300 / 70$ v. B/100 & 0.50
\end{tabular}

$75 \%$ D.N.S.A. Against $100 \%$ D.N.S.A.

Optical Density

B/100 v. B/75

$100 / 100$ v. B/100

$100 / 75$ v. $B / 100$

$300 / 100$ v. $B / 100$

$300 / 75$ v. $B / 100$

0.50

$80 \%$ D.N.S.A. Against $100 \%$ D.N.S.AD

Optical Density

B/100 v. B/80

$100 / 100$ v. B/100

$100 / 80$ v. B/100

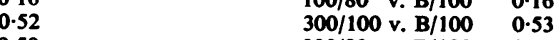

$300 / 80$ v. $B / 100$

0.01

0.17

$0 \cdot 16$

0.51

Each optical density is the mean of 16 readings from resulting quadruplicate estimations on each of four different preparations of solutions. 
TABLE VII

EFFECT OF CONSUMPTION OF D.N.S.A. BY PRECIPITATION OF PROTEIN IN SECOND SERIES OF EXPERIMENTS

Glucose Content ( $\mathrm{mg} . / 100 \mathrm{ml}$.)

\begin{tabular}{ll}
\hline Supernatants & $\begin{array}{l}\text { Reaction } \\
\text { Mixtures }\end{array}$ \\
\hline
\end{tabular}

D.N.S.A. Concentrations $(100 \%=1.75 \mathrm{~g} . / 100 \mathrm{ml}$.)

\begin{tabular}{lllllll}
\hline $100 \%$ & $60 \%$ & $100 \%$ & $70 \%$ & $100 \%$ & $75 \%$ & $100 \%$
\end{tabular}

$\begin{array}{rllllllllll}5 & 2.5 & 0.07 & 0.07 & 0.08 & 0.08 & 0.08 & 0.08 & 0.08 & 0.08 & \text { (row 1) } \\ 10 & 5 & 0.26 & 0.25 & 0.28 & 0.26 & 0.26 & 0.27 & 0.26 & 0.25 & \text { (row 2) } \\ 15 & 7.5 & 0.48 & 0.45 & 0.48 & 0.46 & 0.47 & 0.46 & 0.46 & 0.44 & \text { (row 3) } \\ 20 & 10 & 0.68 & 0.65 & 0.70 & 0.68 & 0.67 & 0.66 & 0.67 & 0.66 & \text { (row 4) } \\ 25 & 12.5 & 0.86 & 0.81 & - & - & 0.86 & 0.85 & 0.86 & 0.84 & \text { (row 5) }\end{array}$

The figures in the body of the table are optical densities of the reaction mixtures against reagent blanks containing D.N.S.A. but no glucose. All experiments were performed in duplicate. Four sets of experiments compared $100 \%$ D.N.S.A with 60 , 70, 75, and 80\% D.N.S.A. It will be seen that the glucose content of the solutions in row 1 is below the minimum necessary for a linear response.

\section{TABLE VIIA}

Equivalent Blood Glucose Concentrations

(mg./100 ml.)

315

$\begin{array}{ll} & 100 \\ 0.22 \\ 0.42\end{array}$

\begin{tabular}{lllllllll}
\hline $100 \%$ & $60 \%$ & $100 \%$ & $70 \%$ & $100 \%$ & $75 \%$ & $100 \%$ & $80 \%$ \\
\hline 0.22 & 0.20 & 0.20 & 0.20 & 0.21 & 0.19 & 0.20 & 0.19 \\
0.42 & 0.40 & 0.42 & 0.42 & 0.41 & 0.39 & 0.41 & 0.41 \\
0.60 & 0.56 & - & - & 0.60 & 0.58 & 0.60 & 0.59
\end{tabular}

These results are extracted from Table VII by deducting the figures in the second row from the figures in the third, fourth and fifth rows. This procedure simulates the situations obtaining when blood specimens containing $105 \mathrm{mg} . / 100 \mathrm{ml}$. to $315 \mathrm{mg} . / 100 \mathrm{ml}$. glucose are processed in the routine technique against reagent blanks employing glucose-D.N.S.A. which contains $10 \mathrm{mg} . / 100 \mathrm{ml}$. glucose.

amount of glucose, and so might be thought worth exploring for routine use. When the volume of D.N.S.A. is reduced to $3 \mathrm{ml}$., the residual D.N.S.A. after protein precipitation (when blood is the test fluid) amounts to some $66 \%$ of the initial concentration. In general this means that the understatement of the resulting glucose content of the blood tested will be exaggerated in comparison with the standard technique; the results then should show an apparent reduction in the glucose content as compared with the standard technique. This effect should be further displayed when the volume of D.N.S.A. solution is reduced to $2.5 \mathrm{ml}$.

To test this prediction, routine blood specimens sent to the laboratory for glucose estimations were used, each being processed with $4 \mathrm{ml}$., $3 \mathrm{ml}$., and $2.5 \mathrm{ml}$. dinitrosalicylic acid. Blanks and standards were processed with each appropriate volume of dinitrosalicylic acid. The glucose content of the specimens ranged from $66 \mathrm{mg} . / 100 \mathrm{ml}$. to $376 \mathrm{mg}$./ $100 \mathrm{ml}$. The sum of the values obtained by each technique was obtained, and these totals compared with each other. Thirty-six specimens were so treated, giving the following cumulative totals:

\begin{tabular}{|c|c|c|}
\hline & Total & $\begin{array}{l}\text { Deficit Relative to Routine } \\
\text { Technique }\end{array}$ \\
\hline $\begin{array}{l}\text { Using } 4 \mathrm{ml} \text {. D.N.S.A. } \\
\text { Using } 3 \mathrm{ml} \text {. D.N.S.A. }\end{array}$ & $\begin{array}{l}5,530 \\
5,256\end{array}$ & $\begin{aligned} & \text { nil } \\
& 274 \div 36= 7.6 \mathrm{mg} . / 100 \mathrm{ml} . \text { per } \\
& \text { estimation }\end{aligned}$ \\
\hline Using $2.5 \mathrm{ml}$. D.N.S.A. & 5,132 & $\begin{array}{c}398 \div 36= \\
\text { estimation }\end{array}$ \\
\hline
\end{tabular}

These figures show the expected effect. If the volume of D.N.S.A. solution were to be reduced to $3 \mathrm{ml}$. in routine work, the slightly reduced chromogenicity at high blood sugar levels would of course show itself more definitely than it does when $4 \mathrm{ml}$. of D.N.S.A. is used. If this were ignored, then the addition of some $8 \mathrm{mg} . / 100 \mathrm{ml}$. (7.6 mg./100 ml. above) to the results would correct them to the level of those obtained with the $4 \mathrm{ml}$. volume of dinitrosalicylic acid. (The series of results with $2.5 \mathrm{ml}$. of D.N.S.A. was included merely to confirm the expected progression.)

EFFECT OF DELAYS AND INTERRUPTIONS After mixing the blood and the glucose-D.N.S.A. delays of up to three or four hours before removing the supernatant from the precipitated protein have a negligible effect upon the results of the estimation (less than $1 \%$ change); after five or six hours' delay the apparent yield of glucose is raised by some $5 \%$. The mechanism of this effect is obscure. It has not seemed sufficiently important to warrant further investigation, as it is abolished by the simple act of removing the supernatant from the precipitated protein at any time up to three hours from the beginning of the procedure.

After adding reagent $B$ to an equal volume of the supernatant, the $p \mathbf{H}$ of the mixture is greater than 12 , so we investigated the effect of delays at this stage. Table VIII shows that delays of up to 20 minutes are without significant effect; after an hour, 
TABLE VIII

EFFECT OF DELAY AFTER ADDING REAGENT B BEFORE HEATING

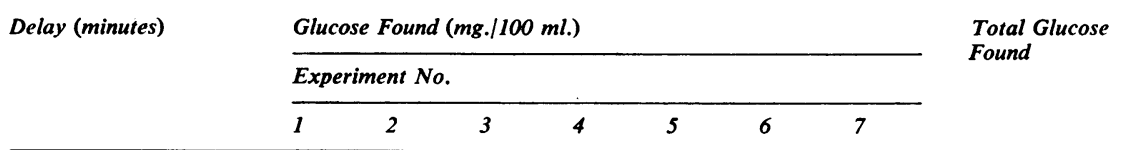

\section{Seven experiments up to 20 minutes}

$\frac{1}{2}$ to 1 (minimum)

$$
10
$$

10

$\begin{array}{ll}214 & 210 \\ 220 & 215\end{array}$

3

Four experiments up to 60 minutes ${ }^{1}$

$\frac{1}{2}$ to 1 (minimum)

$\begin{array}{lll}1 \text { (minimum) } & 214 & 210 \\ 10 & 220 & 215 \\ 20 & 223 & 205 \\ 30 & 222 & 195 \\ 60 & 213 & 195\end{array}$

$\begin{array}{rr}1,038 & 115 \\ 994 & 105 \\ 994 & 107\end{array}$

162

$\begin{array}{rrrrrr}1,038 & 115 & 162 & 103 & 340 & 2,182 \\ 994 & 105 & 156 & 110 & 357 & 2,157 \\ 994 & 107 & 164 & 104 & 377 & 2,174 \\ & & & & & \\ 1,038 & 115 & - & - & - & 1,577 \\ 994 & 105 & - & - & - & 1,534 \\ 994 & 107 & - & - & - & 1,529 \\ 994 & 105 & - & - & - & 1,516 \\ 986 & 105 & - & - & - & 1,499\end{array}$

100 (row 1)

99 (row 2)

99 (row 3)

100 (row 1)

97 (row 2)

97 (row 3)

96 (row 4)

95 (row 5)

${ }^{1}$ One of the specimens involved proved to be from an ante-mortem case; it contained some $1,000 \mathrm{mg} . / 100 \mathrm{ml} . \mathrm{glucose}$.

there is an apparent loss of some $5 \%$. In these experiments quite vigorous shaking was employed to mix the reagents, so that aeration was at least as great as in routine testing.

The effect of varying the time of heating has been shown in Table I above.

After the tubes have been cooled in water at room temperature, delays up to five hours in reading the optical densities of the solutions are without detectable effect. At 24 to 30 hours after cooling, small irregular (inconstant) changes occur in some instances: these have not been explored, in view of the irrelevance of such delays in practice.

ABSORPTION SPECTRUM OF REACTION MIXTURE In the routine technique, the glucose-D.N.S.A. blank (processing $0.2 \mathrm{ml}$. water instead of blood) yields $(400 / 4.2 \times 2)=47.6 \mu \mathrm{g} . / \mathrm{ml}$. glucose in the reaction mixture (subject to minor variation in the glucose content of any particular batch of glucose-D.N.S.A. reagent). Glucose standards containing 100,200 , and $300 \mathrm{mg} . / 100 \mathrm{ml}$. processed as blood in the routine technique yield $71 \cdot 4,95 \cdot 2$, and $119 \mu \mathrm{g} . / \mathrm{ml}$. respectively; these figures represent increments of $23 \cdot 8$, 47.6 , and $71.4 \mu \mathrm{g} . / \mathrm{ml}$. respectively, as compared with the glucose-D.N.S.A. blank. Three sets of experimental data are available, using solutions containing approximately these amounts of glucose. Two of these are summarized in Table IX, the zero setting being made with water; a third set was provided by an earlier experiment in which the zero setting was made against a glucose-D.N.S.A. blank containing $48.8 \mu \mathrm{g} . / \mathrm{ml}$, and the solutions used contained $73 \cdot 2,97 \cdot 6$, and $122 \mu \mathrm{g} . / \mathrm{ml}$. glucose respectively. These three sets of data were used (each set separately) to calculate the increments in optical density to be expected when using a $5 \mathrm{~mm}$. light path (as in routine work) at wavelengths from 500 to
TABLE IX

OPTICAL DENSITIES OF CERTAIN REACTION MIXTURES

\begin{tabular}{|c|c|c|c|c|c|}
\hline \multirow{2}{*}{\multicolumn{2}{|c|}{$\begin{array}{l}\text { Wavelength } \\
(m \mu)\end{array}$}} & \multicolumn{4}{|c|}{ Glucose Content of Reaction Mixture ( $\mu \mathrm{g} . / \mathrm{ml})}$. \\
\hline & & 50 & 75 & 100 & 125 \\
\hline 500 & $\begin{array}{l}\text { (a) } \\
\text { (b) }\end{array}$ & $\begin{array}{l}1 \cdot 50 \\
1 \cdot 60\end{array}$ & $\begin{array}{l}1.65 \\
1.75\end{array}$ & $\begin{array}{l}1.80 \\
1.90\end{array}$ & $\begin{array}{r}1.95 \\
>2.00\end{array}$ \\
\hline 520 & $\begin{array}{l}\text { (a) } \\
\text { (b) }\end{array}$ & $\begin{array}{l}0.417 \\
0.440\end{array}$ & $\begin{array}{l}0.550 \\
0.580\end{array}$ & $\begin{array}{l}0.690 \\
0.720\end{array}$ & $\begin{array}{l}0.815 \\
0.860\end{array}$ \\
\hline 540 & $\begin{array}{l}\text { (a) } \\
\text { (b) }\end{array}$ & $\begin{array}{l}0 \cdot 186 \\
0 \cdot 192\end{array}$ & $\begin{array}{l}0 \cdot 292 \\
0 \cdot 300\end{array}$ & $\begin{array}{l}0.392 \\
0.412\end{array}$ & $\begin{array}{l}0.500 \\
0.515\end{array}$ \\
\hline 560 & $\begin{array}{l}\text { (a) } \\
\text { (b) }\end{array}$ & $\begin{array}{l}0 \cdot 114 \\
0 \cdot 118\end{array}$ & $\begin{array}{l}0 \cdot 190 \\
0 \cdot 200\end{array}$ & $\begin{array}{l}0.265 \\
0 \cdot 278\end{array}$ & $\begin{array}{l}0.343 \\
0.352\end{array}$ \\
\hline 580 & $\begin{array}{l}\text { (a) } \\
\text { (b) }\end{array}$ & $\begin{array}{l}0.076 \\
0.078\end{array}$ & $\begin{array}{l}0 \cdot 128 \\
0 \cdot 136\end{array}$ & $\begin{array}{l}0 \cdot 177 \\
0 \cdot 188\end{array}$ & $\begin{array}{l}0 \cdot 237 \\
0 \cdot 242\end{array}$ \\
\hline 600 & $\begin{array}{l}\text { (a) } \\
\text { (b) }\end{array}$ & $\begin{array}{l}0.050 \\
0.050\end{array}$ & $\begin{array}{l}0.086 \\
0.092\end{array}$ & $\begin{array}{l}0 \cdot 118 \\
0 \cdot 125\end{array}$ & $\begin{array}{l}0.155 \\
0.158\end{array}$ \\
\hline
\end{tabular}

Two sets of figures are shown ( $a$ and $b$ ) from experiments separatef by three weeks and using different batches of reagents.

$600 \mathrm{~m} \mu$, and processing 100, 200, and $300 \mathrm{mg} . / 100 \mathrm{mp}$. glucose standards against a glucose-D.N.S.A. blank. An example of the arithmetic involved is follows: Table IX shows that using a Unicam S.P. 500 spectrophotometer at, e.g., $540 \mathrm{~m} \mu$, with $2 \mathrm{~mm}$ light path and zero set with water, increases of 20 50 , and $75 \mu \mathrm{g} . / \mathrm{ml}$. in the glucose content of the reaction mixture yield respective increments in optical density of $0.106(0.292$ minus 0.186$), 0.206(0.3$, minus 0.186$)$, and $0.314(0.500$ minus 0.186$)$. If these figures are multiplied by $5 / 2$ (change $\mathbb{\text { If }}$ light path from $2 \mathrm{~mm}$. to $5 \mathrm{~mm}$.) and by $23 \cdot 8 / 25 \frac{9}{8}$ (change from experimental glucose concentratio to routine standards) we arrive at the increments optical density to be expected in routine work фif this wavelength were used, and if standards contain- 
TABLE $X$

EXPECTED INCREMENTS IN OPTICAL DENSITY

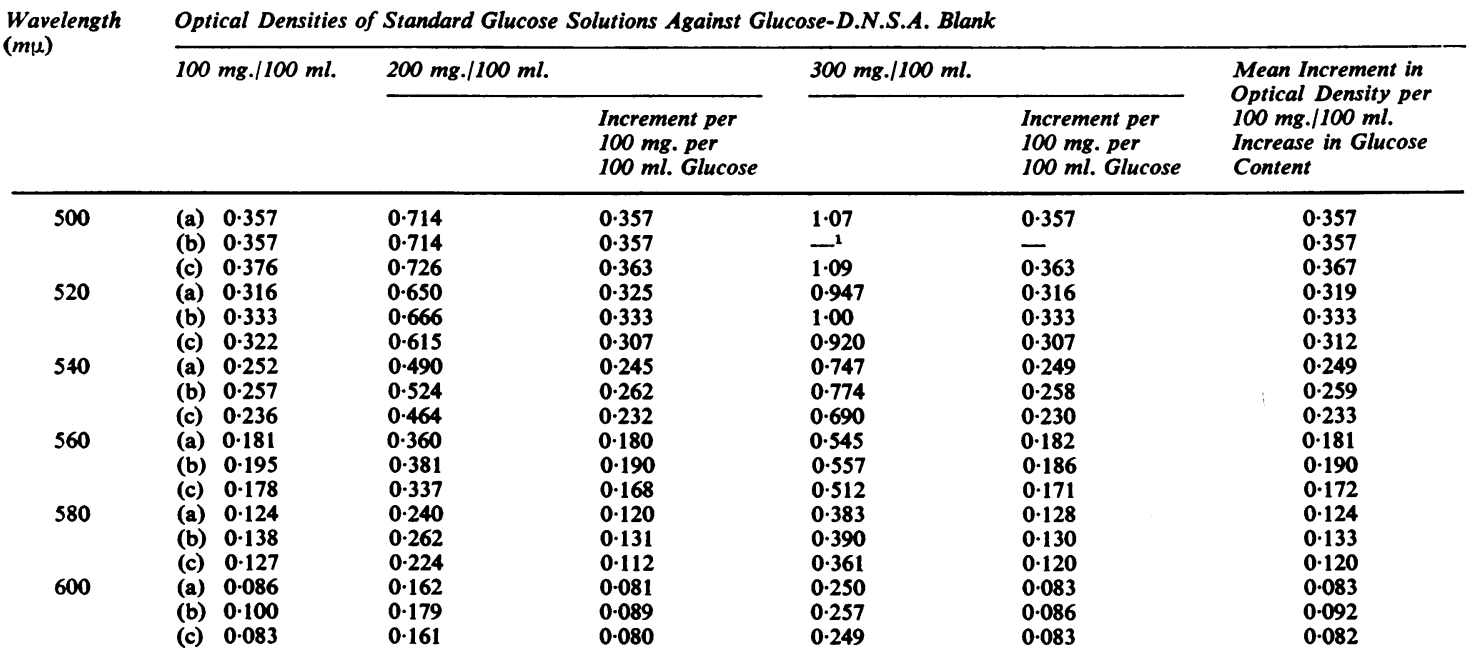

Three sets of figures, $a$ and $b$ derived from Table IX, and $c$ from a third experiment as described in the text, are used to calculate the mean increment in optical density given by each increase of $100 \mathrm{mg} . / 100 \mathrm{ml}$. glucose.

'Original optical density was over 2.00 (i.e., unreadable) against $\mathrm{H}_{2} \mathrm{O}$ (see Table IX).

ing 100,200 , and $300 \mathrm{mg} . / 100 \mathrm{ml}$. glucose were processed against a glucose-D.N.S.A. blank. The product of $5 / 2 \times 23.8 / 25.0$ is 2.38 . The increments derived from Table IX have been multiplied by $2 \cdot 38$. The figures from the third set referred to above needed to be multiplied by $2 \cdot 44$, because of minor differences in experimental layout.

The results of these calculations are summarized in Table $\mathrm{X}$, which shows the three sets of figures separately, as an index of the degree of reproducibility over a period of four to five months using different batches of reagents and different preparations of standard solutions of glucose. The Ilford filter 605 gives optical densities very close to those given at wavelength $560 \mathrm{~m} \mu$ by the S.P. 500 spectrophotometer, around $0 \cdot 18$ per $100 \mathrm{mg}$. $/ 100 \mathrm{ml}$. glucose processed by the routine technique.

REPRODUCIBILITY Table XI summarizes the results of repeat estimations by the routine technique. It must be emphasized that these figures are based on tests done in everyday conditions, repeated in different batches, usually on different days, with different preparations of glucose-D.N.S.A. If repeat estimations within the same batch are considered, the coefficient of variation falls to $2.6 \%$, based upon 70 pairs of estimations. It will be seen that the coefficient of variation is slightly higher (at $4.75 \%$ ) in the range of tests containing less than $100 \mathrm{mg}$./ $100 \mathrm{ml}$. glucose than in the remainder (at approxi- mately $3.5 \%$ ); this no doubt reflects the effect of the high-blank element due to the use of glucose dinitrosalicylic acid.

\section{TABLE XI}

COEFFICIENT OF VARIATION OF THE ROUTINE TECHNIQUE BASED ON REPEAT ESTIMATIONS IN DIFFERENT BATCHES Specimens containing:

Coefficient of Variation $(\%)$

< $100 \mathrm{mg} . / 100 \mathrm{ml}$. glucose

(128 estimations; 55 duplicates, 6 triplicates) $\quad 4.75$

100 to $200 \mathrm{mg} . / 100 \mathrm{ml}$. glucose

(125 estimations; 31 duplicates, 21 triplicates)

$>200 \mathrm{mg} . / 100 \mathrm{ml}$. glucose

(43 estimations; 11 duplicates, 7 triplicates)

Totals (296 estimations; 97 duplicates, 34 triplicates)

Comparison with the glucose-oxidase technique of Marks (1959), which appears to be the most stable and accurate glucose-specific technique available at present (1961), is of interest in regard to reproducibility. Marks (1959) states that the coefficient of variation of repeat estimations is $2.1 \%$; but this appears to be calculated on only 10 replicates done in one and the same batch. We have obtained the corresponding figure for the glucose-oxidase technique in different batches, based on 78 estimations (39 duplicates) of blood specimens containing from 
72 to $552 \mathrm{mg} . / 100 \mathrm{ml}$. glucose, and in our hands the coefficient of variation in these conditions is $3.1 \%$, which confirms the precision of this method.

RECOVERY OF ADDED GLUCOSE Table XII shows that in six experiments recovery ranged from $86 \%$ to $105 \%$, the mean being $99 \%$.

\section{TABLE XII}

GLUCOSE RECOVERY DATA IN SIX EXPERIMENTS

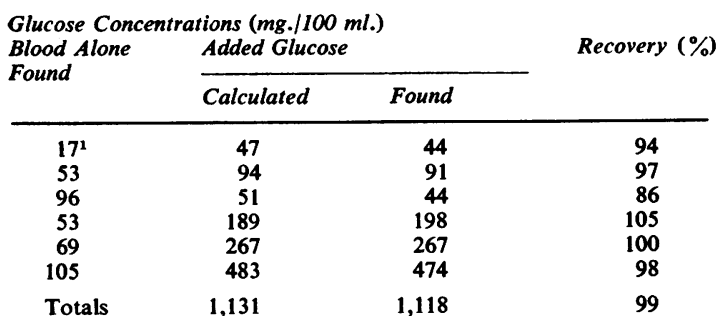

'Figures are the means of triplicate estimations by the routine technique.

COMPARISON OF RESULTS WITH THOSE OF OTHER STANDARD METHODS Blood and cerebrospinal fluid were used as test fluids.

Blood as test fluid Figure 2 shows the relation between the results obtained by the D.N.S.A. method and those obtained by the Hagedorn and Jensen method in routine use before the adoption of the D.N.S.A. method.

Figure 3 shows the relation between the results obtained by the D.N.S.A. method and the glucoseoxidase technique (Marks, 1959).

A good estimate of the comparative specificity of the different techniques is afforded by summing the values (in $\mathrm{mg}$./ $100 \mathrm{ml}$.) obtained for each specimen and comparing the resulting totals. Any systematic difference is thus free to appear, unaffected by variations in individual estimations.

\begin{tabular}{|c|c|c|}
\hline $\begin{array}{l}\text { Hagedorn and Jensen and D.N. } \\
\text { Compared }\end{array}$ & $\begin{array}{l}\text { Hagedorn } \\
\text { and Jensen }\end{array}$ & D.N.S.A. \\
\hline 152 routine estimations & totalling $\rightarrow$ Ratio 1 & Ratio $100: 99 \cdot 7$ \\
\hline $\begin{array}{l}\text { Glucose-Oxidase and D.N.S.A. } \\
\text { Compared }\end{array}$ & $\begin{array}{l}\text { Glucose } \\
\text { Oxidase }\end{array}$ & D.N.S.A. \\
\hline & $\begin{aligned} & \text { totalling } \rightarrow \mathbf{1 1 , 8 7 4}, \\
& \text { Ratio }\end{aligned}$ & $\begin{array}{l}11,907 \\
00 \cdot 3\end{array}$ \\
\hline
\end{tabular}

These figures show that the D.N.S.A. results are very close to true glucose values, taking the figures as they stand, without 'correcting' the D.N.S.A. figures for loss of D.N.S.A. by protein precipitation. Indirectly these figures also indicate that the Hagedorn and Jensen method in the conditions of

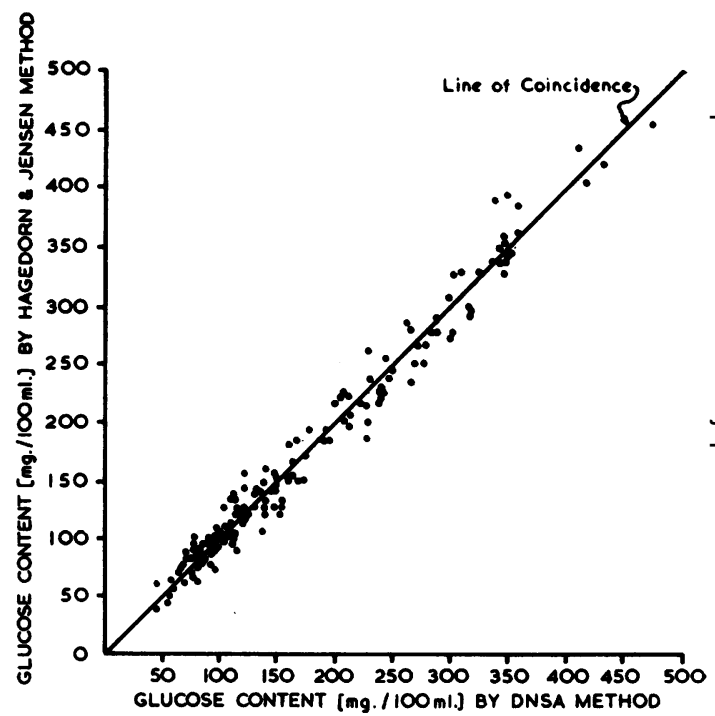

FIG. 2. Glucose content of blood specimens by Hagedorn $\bigcirc$ and Jensen and D.N.S.A. methods (152 specimens).

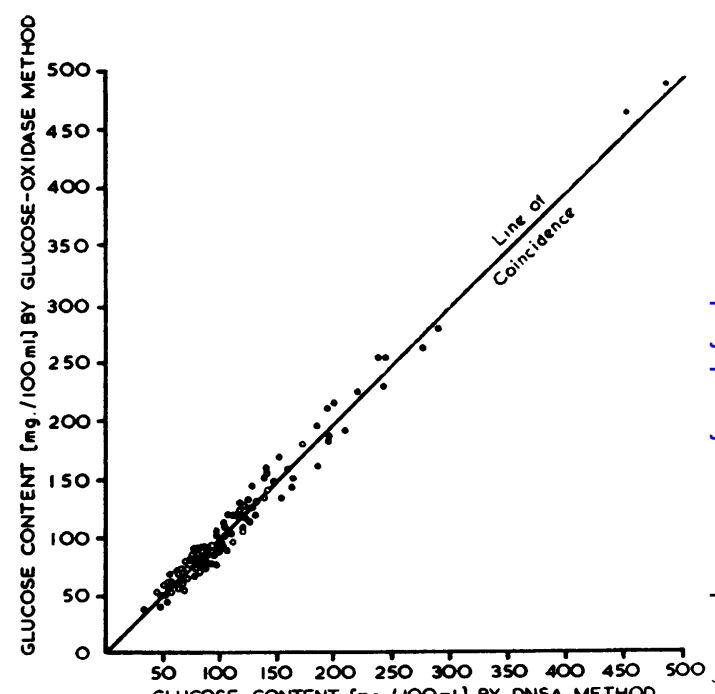

FIG. 3. Glucose content of blood (O) (89 specimens) and w C.S.F. (O) (29 specimens) by glucose-oxidase and D.N.S.A methods.

routine work gives (in our hands) results which are $100.6 \%$ of true glucose values $\left(1,000 / 997 \times 1,003 / \frac{\pi}{0}\right.$ 1,000). Harrison (1957) quotes Herbert and Bourne $(1930,1931)$ to the effect that some $4 \mathrm{mg} / 100 \mathrm{ml} \stackrel{?}{?}$ should be deducted from the results obtained by the original Hagedorn and Jensen technique to give the true glucose values. Our own results by that technique 
are a little lower than this statement would lead one to expect. We think that the explanation lies in a small loss of glucose in the conditions of routine work, due to slightly inadequate washing of the precipitate with hot water.

Cerebrospinal fluid as test fluid When fluids other than blood are being tested, the two compensating factors previously referred to, the loss of D.N.S.A. by protein precipitation and the presence of nonglucose reducing substances found in blood, are both absent.

The amount of protein in cerebrospinal fluid is never of significant effect in terms of loss of dinitrosalicylic acid. In order to demonstrate the lack of effect of non-glucose reducing substances in routine specimens of cerebrospinal fluid, we estimated the sugar content of 29 specimens, among which were included some from diabetic patients in whom the values were 180,140 , and $125 \mathrm{mg}$./100 ml. In none of these did the D.N.S.A. technique give significantly differant values from the glucose-oxidase technique (Fig. 3).

The totals of the 29 estimations were by the glucose-oxidase technique 2,287 (mean $=79 \mathrm{mg}$./ $100 \mathrm{ml}$.) and by the D.N.S.A. technique 2,335 (mean $=80.5 \mathrm{mg} . / 100 \mathrm{ml}$.).

In view of the virtual impossibility of obtaining a 'repeat' specimen of cerebrospinal fluid, and the prevalence of low glucose values, we prefer to perform the D.N.S.A. technique in duplicate with such specimens. The duplication adds little to the work involved or the time required, as the technique is so simple: and the coefficient of variation of the mean of the two results may be assumed to lie in the region of $(4.75 \% \times 1 / \sqrt{ } 2)=3.4 \%$. (This is calculated with reference to the coefficient of variation of single estimations on blood specimens containing less than $100 \mathrm{mg} . / 100 \mathrm{ml}$. glucose, and is therefore likely to be an overestimate of the variation rather than an underestimate.) In practice this means that the result of the duplicate estimation of glucose in cerebrospinal fluid will in 19 cases out of 20 lie within the range $\pm 6.8 \%$ of the true figure. When the figure obtained is, for example, $50 \mathrm{mg} . / 100 \mathrm{ml}$. then there is a $95 \%$ chance that the true value lies within the range 46.6 to $53.4 \mathrm{mg} . / 100 \mathrm{ml}$.

\section{EFFECT OF SUBSTANCES OTHER THAN GLUCOSE}

GLUTATHIONE A solution of glutathione containing $100 \mathrm{mg}$. per $100 \mathrm{ml}$. was processed as blood. No colour was produced.

UREA Solutions containing $1,000 \mathrm{mg} . / 100 \mathrm{ml}$., $500 \mathrm{mg} . / 100 \mathrm{ml}$., and $200 \mathrm{mg} . / 100 \mathrm{ml}$., processed as blood, gave no colour.
OTHER HEXOSES Equimolar solutions of galactose, mannose, and fructose gave a colour development indistinguishable from that given by glucose.

LACTOSE Solutions of lactose containing 100, 200, and $400 \mathrm{mg} . / 100 \mathrm{ml}$. were processed as blood; they gave a colour development of which the glucose equivalent was 78,149 , and $297 \mathrm{mg}$./100 ml., i.e., almost exactly three-quarters of the intensity of that given by glucose solutions.

ASCORBIC ACID Solutions of ascorbic acid were made and processed as blood, with precautions against avoidable losses by oxidation. The results were as follows:

\begin{tabular}{ccc}
$\begin{array}{l}\text { Concentration of } \\
\text { Ascorbic Acid } \\
(\mathrm{mg} . / 100 \mathrm{ml} .)\end{array}$ & Optical Density & $\begin{array}{l}\text { Glucose Equivalent } \\
(\mathrm{mg} . / 100 \mathrm{ml} .)\end{array}$ \\
\hline 25 & 0.02 & 11 \\
50 & 0.04 & 23 \\
100 & 0.08 & 46 \\
200 & 0.16 & 91 \\
400 & 0.39 & 223
\end{tabular}

Glucose standard $200 \mathrm{mg} . / 100 \mathrm{ml}$. gave an optical density of 0.35

CYSTEINE Sumner and Sisler (1944) remark that cysteine increases the amount of colour developed by a given amount of glucose. We have confirmed this finding and have explored the possibility of utilizing it in a routine technique. Unfortunately for this purpose, the amount of enhancement of the colour developed by a given amount of glucose is linked quite markedly with the concentration of D.N.S.A. remaining in the final reaction tube; so much so, that small variations in the residual D.N.S.A. (due for instance to small variations in the protein content of the specimens being tested) have significant effects on the apparent glucose content when D.N.S.A. is used as the protein precipitant. Table XIII gives relevant figures.

It would probably be feasible to devise a technique using cysteine, precipitating proteins with some reagent other than D.N.S.A.; in such a procedure the simplicity of the D.N.S.A. technique would be lost, and the method would have little to commend it compared with other established techniques.

CERTAIN ANTIBIOTICS The substances listed below were processed as blood (in duplicate) in concentrations of $1,000 \mu \mathrm{g} . / \mathrm{ml}$., because it may be necessary occasionally to estimate the glucose content of body fluids and exudates containing these substances.

Streptomycin Strepolin '33', streptomycin sulphate injection B.P. (Glaxo), ' 333,000 units streptomycin per $\mathrm{ml}$. with stabilizing agents and $0.5 \%$ phenol'. Glucose equivalent by D.N.S.A. technique $=$ nil $\rightarrow$ trace. 
TABLE XIII

EFFECT OF L-CYSTEINE HYDROCHLORIDE IN ENHANCING CHROMOGENICITY OF D.N.S.A.-GLUCOSE REACTION

Concentration of Cysteine $(\mathrm{g} . / 100 \mathrm{ml}$.)

Initial in D.N.S.A. Final in Reaction Mixture
$(g . / 100 \mathrm{ml}$.)

0.4

0.5

$0 \cdot 6$

0.7

0.8

0.9 $(\mathrm{g} . / 100 \mathrm{ml}$.)

\section{$0 \cdot 196$}

0.245

$0 \cdot 294$

0.343

0.392

0.441

Optical Densities $(\times 100)$ against Reagent Blank Concentration of Glucose in Test Solutions (mg./100 ml.)

\begin{tabular}{|c|c|c|c|c|}
\hline 50 & 100 & 150 & 200 & 250 \\
\hline 14 & 32 & 50 & 68 & 83 \\
\hline 14 & 32 & 48 & 66 & 84 \\
\hline $18^{1}$ & $37^{1}$ & $56^{1}$ & $74^{1}$ & $88^{1}$ \\
\hline $18^{1}$ & $37^{1}$ & $55^{1}$ & $75^{1}$ & $88^{1}$ \\
\hline 15 & 36 & 50 & 69 & 85 \\
\hline 15 & 35 & 45 & 66 & 76 \\
\hline
\end{tabular}

Preliminary experiments indicated that the optimal concentration of cysteine in $1.75 \mathrm{~g} . / 100 \mathrm{ml} . \mathrm{D} . \mathrm{N} . \mathrm{S} . \mathrm{A}$. lay at around 0.6 to $0.7 \mathrm{~g} . / 100 \mathrm{ml}$ (giving some 0.29 to $0.34 \mathrm{~g} . / 100 \mathrm{ml}$. in the reaction mixture). Three times this concentration inhibited the colour reaction altogether. Volumes of water and of glucose solutions, $0.20 \mathrm{ml}$. of each, were added to $5.0 \mathrm{ml}$. volumes of cysteine-D.N.S.A. reagent, and 5.0 ml. volumes of reagent B were added and heated for six minutes as usual. Optical densities were measured in 10 mm. cuvettes with an Ilford 605 filter(maximum absorption at $550 \mathrm{~m} \mu$ ).

${ }^{1}$ Dose-response is close to a straight line in these rows. Test fluids were diluted $1 / 26$ (before addition of reagent B) as compared with $1 / 21$ in routine work. Apart from this, extinctions are similar to those found in the routine technique when allowance is made for change in light path 8 It follows that the chromogenicity when cysteine is used amounts to some $26 / 21$ times that found in the routine technique, an increase of some $24 \%$.

TABLE XIIIA

EFFECT OF CONSUMPTION OF D.N.S.A. BY PROTEIN-PRECIPITATION USING CYSTEINE

\begin{tabular}{|c|c|c|c|c|c|c|c|}
\hline \multirow{3}{*}{$\begin{array}{l}\text { Glucose in } \\
\text { Test Fluid } \\
(\mathrm{mg} . / 100 \mathrm{ml} .)\end{array}$} & \multicolumn{7}{|c|}{ Optical Densities $(\times 100)$ against Reagent Blanks } \\
\hline & \multirow{2}{*}{$\begin{array}{l}\text { Blank and } \\
\text { Tests in } \\
100 \% \text { D.N.S.A. }\end{array}$} & \multicolumn{2}{|c|}{ Tests in $75 \%$ D.N.S.A. Against } & \multicolumn{2}{|c|}{ Tests in $70 \%$ D.N.S.A. Against } & \multicolumn{2}{|c|}{ Tests in $65 \%$ D.N.S.A. Against } \\
\hline & & $100 \%$ Blank & $75 \%$ Blank & $100 \%$ Blank & $70 \%$ Blank & $100 \%$ Blank & $65 \%$ Blank \\
\hline $\begin{array}{l}100 \\
200\end{array}$ & $\begin{array}{l}38 \\
77\end{array}$ & $\begin{array}{l}31 \\
67\end{array}$ & $\begin{array}{l}39 \\
76\end{array}$ & $\begin{array}{l}28 \\
65\end{array}$ & $\begin{array}{l}39 \\
76\end{array}$ & $\begin{array}{l}24 \\
58\end{array}$ & $\begin{array}{l}36 \\
70\end{array}$ \\
\hline
\end{tabular}

Glucose solutions were processed as above, but in varying concentrations of D.N.S.A. (Notation in regard to D.N.S.A. is as used in Tables@ VI and VII.)

The D.N.S.A. consumption effect is so large that errors of the order of 20 to $30 \mathrm{mg} . / 100$ ml. would arise in routine sugar estimations unless a $\overrightarrow{\bar{O}}$ correction factor were applied. The proper correction factor would vary between 0.08 and $0 \cdot 12$, depending upon the amount of protein in the 3 test fluid. This imprecision would be too great for reliable results to be obtained.

Celbenin (BRL 1241) Sodium 6-(2, 6-dimethoxybenzamido) penicillanate monohydrate (Beecham $\mathrm{Re}-$ search Laboratories Ltd.). Glucose equivalent by D.N.S.A. technique $=$ nil $\rightarrow$ trace.

Benzylpenicillin B.P. (sodium salt) (Distillers Co. [Bioćhemicals] Ltd.), 1,665 i.u./mg. glucose equivalent by D.N.S.A. technique $=$ nil $\rightarrow$ trace .

Tetracycline Achromycin hydrochloride (Lederle) buffered with ascorbic acid 'containing not less than 90,000 units per $100 \mathrm{mg}$.'. Glucose equivalent by D.N.S.A. technique $=138 \mathrm{mg} . / 100 \mathrm{ml}$.; this is at least partly due to the ascorbic acid content.

Oxytetracycline Terramycin (Pfizer) for intramuscular injection. Each $1.0 \mathrm{ml}$. contains $50 \mathrm{mg}$. oxytetracycline hydrochloride, $50 \mathrm{mg}$. magnesium chloride hexahydrate, and $2 \%(w / v)$ procaine hydrochloride. Glucose equivalent by D.N.S.A. technique $=38 \mathrm{mg} .100 \mathrm{ml}$.

Procaine hydrochloride B.P. Isotonic solution $2 \%$ (w/v) containing $0.2 \%(w / v)$ chlorocresol. Tested at a dilution of $1 / 20$ in water; $1 / 20$ of $2 \%(w / v)=0.1 \%$ $(\mathrm{w} / \mathrm{v})=1,000 \mu \mathrm{g} . / \mathrm{ml}$. Glucose equivalent by D.N.S.A technique $=$ nil.

We are grateful to Miss M. F. Crowley, Principalo Biochemist to the Archway Group of Hospitals, for technical assistance.

\section{REFERENCES}

Hall, D. A. (1950). Brit. med. J., 1, 351.

Harrison, G. A. (1957). Chemical Methods in Clinical Medicine, 4th ed., p. 191. Churchill, London.

Herbert, F. K., and Bourne, M. C. (1930). Biochem. J., 24, 299 and ${ }^{C \omega}$ 1787.

(1931). Brit. med. J., 1, 94

Lee, J. (1954). Ibid., 2, 1087.

Leech, R. S., and Woodford, N. (1948). J. Lab. clin. Med., 33, 644 .

Marks, V. (1959). Clin. Chim. Acta, 4, 395.

Sumner, J. B. (1921). J. biol. Chem., 47, 5.

- (1924). Ibid., 62, 287.

- (1925). Ibid., 65, 393.

_- , and Sisler, E. B. (1944). Arch. Biochem., 4, 333. 